\title{
ELECTRONIC PROPERTIES OF Sn- OR Ge-DOPED $\mathrm{In}_{2} \mathrm{O}_{3}$ SEMICONDUCTORS
}

\author{
S.J. WEN, AND G. CAMPET \\ Laboratoire de Chimie du Solide du CNRS, University of Bordeaux I, 351 Cours de la Libération, \\ 33405 Talence (FRANCE)
}

\begin{abstract}
The thermoelectric power and Hall effect of $\operatorname{In}_{2} \mathrm{O}_{3}$ single crystals, either undoped or Sn doped, and of $\mathrm{In}_{2} \mathrm{O}_{3}$ ceramics, either undoped or $\mathrm{Sn}$ or $\mathrm{Ge}$ doped, are investigated. All doped samples have negative thermoelectric power values. The metal-type conductivity occurs when the carrier concentration exceeds $10^{19} \mathrm{~cm}^{-3}$. The correspondence between the values of the thermoelectric power and those of the carrier mobility and carrier concentration is given. Most interestingly this study puts into light the enhanced carrier mobility occurring for Ge-doped $\mathrm{In}_{2} \mathrm{O}_{3}$ samples compared with ITO samples (Sn-doped $\operatorname{In}_{2} \mathrm{O}_{3}$ ) widely used in optoelectronic devices.
\end{abstract}

\section{INTRODUCTION}

Over the past 30 years, a great interest has focused on the development of transparent electrode materials such as Sn-doped $\operatorname{In}_{2} \mathrm{O}_{3}$ commonly labeled ITO, and their optical and electrical properties have been investigated in detail [1-4]. Indeed, the optical and electrical properties of transparent conductive electrodes are very important for optoelectronic-related applications such as electrochromic applications, and could limit the performances for large surface devices such as smart windows. One indeed needs to obtain the lowest possible resistance associated with the highest possible optical transmission in the visible spectrum. Closely related to that, one has to emphasize that the influence of the nature of the doping element on the electronic properties of $\operatorname{In}_{2} \mathrm{O}_{3}$ based semiconductors is not yet clearly established. Therefore, an important question still arises: can the electrical and optical properties of well-known ITO be improved by using dopants other than Sn (partially or totally substituted to $\mathrm{Sn}$ )? With the aim in mind to answer this question, we investigate here the thermoelectric power and Hall effect on a series of $\operatorname{In}_{2} \mathrm{O}_{3}$ based samples either undoped or doped with $\mathrm{Sn}$ or $\mathrm{Ge}$. For sake of clarity, this preliminary investigation will be carried out here on single crystals and ceramics only.

* The authors are grateful to J.P. Chaminade for kindly providing us with single crystals and G. Couturier for helpful assistance. 


\section{PRELIMINARY CONSIDERATIONS RELATED TO THE THERMOELECTRIC POWER}

The thermoelectric power $\alpha$ is proportional to the thermo-emf, $\Delta \mathrm{E}_{\mathrm{E}}-\Delta \mathrm{E}_{\mathrm{T}}$, divided by the temperature drop $\Delta \mathrm{T}$ across the sample:

$\alpha=\left(\Delta \mathrm{E}_{\mathrm{E}}-\Delta \mathrm{E}_{\mathrm{T}}\right) / \Delta \mathrm{T}$

One considers here that electron-carriers predominantly influence the evolution, with temperature, of the thermo-emf (as it occurs for Sn-doped $\operatorname{In}_{2} \mathrm{O}_{3}$ ). The terms on the right-hand side refer to potential $\left(\Delta \mathrm{E}_{\mathrm{E}}\right)$ and kinetic energy $\left(\Delta \mathrm{E}_{\mathrm{T}}\right)$ respectively; they are both measured relative to the energy at the edge of the band (namely the conduction band for the $\mathrm{In}_{2} \mathrm{O}_{3}$-based semiconductors investigated here [1-4]). write:

In the case of a non-degenerate semiconductor, to a first approximation one can

$\alpha_{1}=-\mathrm{k}\left(2-\mu^{*}\right) / \mathrm{q}$

$\alpha_{\mathrm{i}}=-\mathrm{k}\left(4-\mu^{*}\right) / \mathrm{q}$

where $\alpha_{1}$ and $\alpha_{\mathrm{i}}$ symbolize the thermoelectric power for the case of carrier scattering mainly limited by phonons and by ions respectively, $\mathrm{k}$ is the Boltzmann constant, and $\mathrm{q}$ the electronic charge. $\mu^{*}$ is dimensionless and is known as the reduced electrochemical potential. Under such a circumstance, the dependence of $\alpha$ as a function of the conduction-band electron density $n$ can be evaluated. Indeed, $n$ can be expressed as:

$\mathrm{n}=\left(\pi \mathrm{N}_{\mathrm{c}} \mathrm{e} \mu^{*}\right) / 2$

where $\mathrm{N}_{\mathrm{c}}$ represents the effective density of states in the conduction band. Therefore, expressions (2) and (3) become, respectively:

$\alpha_{1}=\mathrm{k} / \mathrm{q}\left\{2-\ln \left(2 \mathrm{n} / \Pi^{1 / 2} \mathrm{~N}_{\mathrm{c}}\right)\right\}$
$\alpha_{\mathrm{i}}=\mathrm{k} / \mathrm{q}\left\{4-\ln \left(2 \mathrm{n} / \Pi^{1 / 2} \mathrm{~N}_{\mathrm{c}}\right)\right\}$

In the degenerate-semiconductor case $\left(\mu^{*}>0\right)$, we have:

$$
\begin{aligned}
& \alpha_{1}=-\mathrm{k} \pi^{2} /\left(\mathrm{q} 3 \mu^{*}\right) \\
& \alpha_{\mathrm{i}}=-\mathrm{k} \pi^{2} /\left(\mathrm{q}\left(\pi^{2}+\mu^{* 2}\right)\right)
\end{aligned}
$$

Equations (7) and (8) are rather similar to those generally used for metals [5].

\section{EXPERIMENTAL PROCEDURE}

\section{(i) Single crystal manufacturing}

Either undoped or Sn-doped $\mathrm{In}_{2} \mathrm{O}_{3}$ (IO) single crystals have been manufactured. The undoped IO single crystals were grown by two methods: (i) the flux method 
as described by J.P. Remeika [6], (ii) the vapor phase technique as described by R.L. Weiher [7]. These two methods generally yield high- and low-carrier concentration, respectively [2]. In order to get appropriate high conductivity, the flux method, uniquely, was used to grow the Sn-doped IO single crystals.

\section{(ii) Ceramics manufacturing}

Either undoped $\mathrm{In}_{2} \mathrm{O}_{3}$ (IO) ceramics or IO ceramics doped with $\mathrm{Sn}$ or Ge have been manufactured. The undoped ceramics were prepared by sintering pellets $(10$ $\mathrm{mm}$ diameter, $1 \mathrm{~mm}$ thick) in air at various temperatures $\left(110{ }^{\circ} \mathrm{C}, 1200{ }^{\circ} \mathrm{C}, 1300\right.$ ${ }^{\circ} \mathrm{C}$ and $1350{ }^{\circ} \mathrm{C}$ ) during $24 \mathrm{~h}$ with a heating and cooling rate of $100{ }^{\circ} \mathrm{C} / \mathrm{h}$. The doped $\mathrm{In}_{2} \mathrm{O}_{3}$ ceramics were prepared by intimately mixing the starting material oxides (i.e., $\mathrm{In}_{2} \mathrm{O}_{3}+\mathrm{SnO}_{2}$ or $\mathrm{GeO}_{2}$ ). The mixed powders were cold-pressed in a steel die and then submitted to an isostatic pressure of 5 bars. The obtained pellets were sintered in air at $1350{ }^{\circ} \mathrm{C}$ for $24 \mathrm{~h}$ after heating to temperature at $100{ }^{\circ} \mathrm{C} / \mathrm{h}$; they were subsequently cooled at $100{ }^{\circ} \mathrm{C} / \mathrm{h}$.

All electrical measurements were performed using equipment described elsewhere $[2,8]$.

\section{RESULTS AND DISCUSSION}

\section{(i) Single crystals}

Values of the room temperature conductivity $\sigma$, carrier concentration $\mathrm{n}$, and carrier mobility $\mu$ of undoped $\mathrm{In}_{2} \mathrm{O}_{3}$ single crystals and of $\mathrm{Sn}$-doped $\mathrm{In}_{2} \mathrm{O}_{3}$ single crystals are given in table $\mathrm{I}$. The reported values were deduced from Hall effect measurements [2].

The thermoelectric power of all samples has similarly been investigated at room temperature. Fig. 1 illustrates the dependence of the thermoelectric power $\alpha$ on the electron density $\mathrm{n}$. For $\mathrm{n} \leqslant 10^{19} \mathrm{~cm}^{-3}, \alpha$ varies proportionally as $\log (\mathrm{n})$ (straight line on fig. 1). Such an evolution is predictable, as it obeys relation (5) and/or (6). On the other hand, for higher carrier concentration the proportionality is not observed because equations (2)-(6) are no longer valid; in fact $\alpha$ varies as $n^{2 / 3}$, as it often occurs for strong degeneracy $\left(\mathrm{n} \geqslant 10^{20} \mathrm{~cm}^{-3},[9]\right)$.

These experimental results enable us to find the degree of degeneracy of the electron gas depicted by $\mu^{*}$. Using the values of $\mu^{*}$, deduced from equation (3) for instance, and the dependence of $\mu^{*}$ on the carrier density (equation (4)), we can evaluate, for the non-degenerate situation, the evolution of the carrier effective mass $m_{N}$ as a function of the density of the conduction-band energy-states $\mathrm{Nc}$. As an illustrative example, one would get for (totally) non-degenerated n-type $\operatorname{In}_{2} \mathrm{O}_{3}$ : $\mathrm{m}_{\mathrm{N}} / \mathrm{m}_{0}=0.42\left(\mathrm{~m}_{0}=\right.$ free-electron mass). This ratio is indeed calculated from the values $\mu^{*}=-1.3$ and $\mathrm{n}=10^{18} \mathrm{~cm}^{-3}$, obtained by extrapolating the doted line (non-degenerated case) of Fig. 1. All these values of $\mathrm{m}_{\mathrm{N}} / \mathrm{m}_{0}, \mu^{*}$, and $\mathrm{n}$ are in good agreement with the literature report for slightly n-type doped $\operatorname{In}_{2} \mathrm{O}_{3}$ thin films [1]. 
TABLE I

Values of the room temperature conductivity, carrier concentration and carrier mobility for the undoped (1 to 5) and $\mathrm{Sn}$ doped $\mathrm{In}_{2} \mathrm{O}_{3}$ (A to D) single crystals [2].* The ratio $\mathrm{Sn} /(\mathrm{In}+\mathrm{Sn}$ ) corresponds to $10^{-2}$ in $\operatorname{In}_{2-2 x} \mathrm{Sn}_{2 x} \mathrm{O}_{3}[2]$.

\begin{tabular}{|c|c|c|c|c|}
\hline $\begin{array}{l}\mathrm{Sn} /(\text { In }+\mathrm{sn}) \text { ratio* } \\
(\% \text { values })\end{array}$ & $\begin{array}{l}\text { Sample } \\
\text { symbol. }\end{array}$ & $\begin{array}{l}\mu \\
\left(\mathrm{cm}^{2} \mathrm{v}^{-1} \mathrm{~s}^{-1}\right)\end{array}$ & $\begin{array}{l}\mathrm{n} \\
\left(\mathrm{cm}^{-3}\right)\end{array}$ & $\begin{array}{l}\sigma \\
\left(\mathrm{cm}^{-1} \Omega^{-1}\right)\end{array}$ \\
\hline $\mathrm{Sn} /(\mathrm{In}+\mathrm{Sn})=0$ & 1 & 85 & $2.5 \times 10^{18}$ & $3.4 \times 10^{1}$ \\
\hline $\mathrm{Sn} /(\mathrm{In}+\mathrm{Sn})=0$ & 2 & 70 & $3.98 \times 10^{18}$ & $4.5 \times 10^{1}$ \\
\hline $\mathrm{Sn} /(\mathrm{In}+\mathrm{Sn})=0$ & 3 & 65 & $1.0 \times 10^{19}$ & $1.04 \times 10^{2}$ \\
\hline $\mathrm{Sn} /(\mathrm{In}+\mathrm{Sn})=0$ & 4 & 58 & $1.4 \times 10^{19}$ & $1.3 \times 10^{2}$ \\
\hline $\mathrm{Sn} /(\mathrm{In}+\mathrm{Sn})=0$ & 5 & 45 & $1.8 \times 10^{19}$ & $1.3 \times 10^{2}$ \\
\hline $\operatorname{Sn}(\mathrm{In}+\mathrm{Sn})=0.25$ & A & 48 & $3.8 \times 10^{19}$ & $2.92 \times 10^{2}$ \\
\hline $\operatorname{Sn}(\operatorname{In}+\operatorname{Sn})=0.5$ & B & 62 & $7.8 \times 10^{19}$ & $7.74 \times 10^{2}$ \\
\hline $\operatorname{Sn}(\operatorname{In}+\mathrm{Sn})=0.8$ & $\mathrm{C}$ & 100 & $1.6 \times 10^{20}$ & $2.56 \times 10^{3}$ \\
\hline Sn $(I n+S n)=0.9$ & D & 81 & $2.8 \times 10^{20}$ & $3.63 \times 10^{3}$ \\
\hline
\end{tabular}

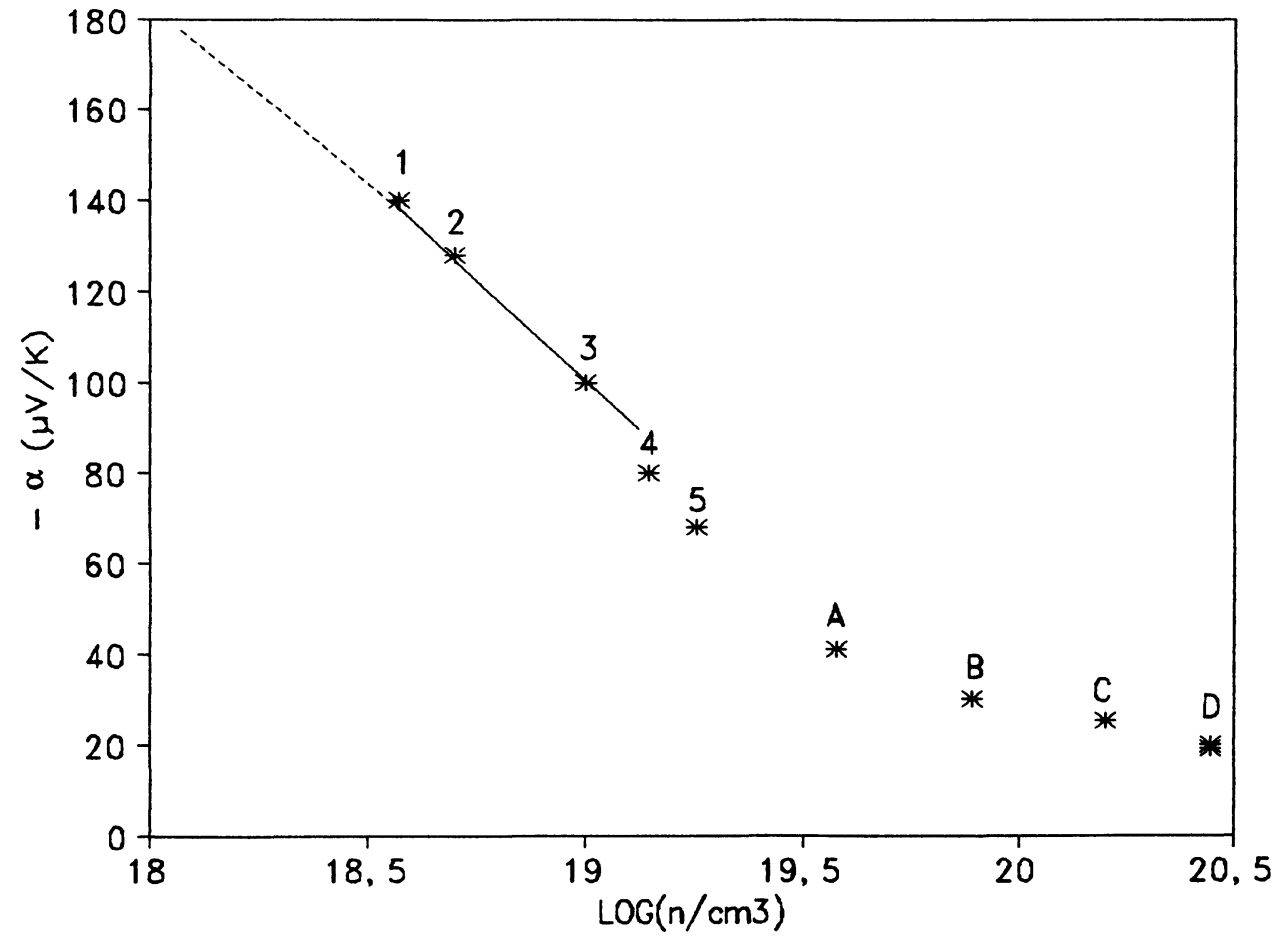

FIGURE 1 Dependence of the thermoelectric power on the electron density in undoped and Sn doped $\mathrm{In}_{2} \mathrm{O}_{3}$ single crystals at $300 \mathrm{~K}$. The sample symbolization is similar to that depicted in table $\mathrm{I}$. 


\section{(ii) Polycrystalline ceramics}

Values of the room temperature conductivity, carrier concentration, and carrier mobility, measured by Hall effect [3] for undoped and for Sn- or Ge-doped $\operatorname{In}_{2} \mathrm{O}_{3}$ are shown in Table II. Fig. 2 illustrates, for samples a to $n$ (Table II), the dependence of the thermoelectric power on the electron density.

The thermoelectric power, like the mobility, is governed by the scattering mechanism of carriers; therefore, we could expect different values of $\alpha$ for $\operatorname{In}_{2} \mathrm{O}_{3}$ doped with different impurities. That is illustrated hereafter for heavily doped samples. It is indeed evident from Fig. 2 that $\alpha$ values, referring to samples $\mathrm{k}-\mathrm{n}$ and symbolizing $\operatorname{In}_{2} \mathrm{O}_{3}$ doped with $\mathrm{Ge}$ for which $\mathrm{n}=10^{20} \mathrm{~cm}^{-3}$, are somewhat higher than those referring to samples $\mathrm{f}-\mathrm{i}$, which represent $\mathrm{In}_{2} \mathrm{O}_{3}$ doped with $\mathrm{Sn}$ and for which $\mathrm{n}=10^{20} \mathrm{~cm}^{-3}$. This can be understood using, for the sake of simplicity, equation (7), which is valid in the strongly degenerate case $\left(\mathrm{n}=10^{20} \mathrm{~cm}^{-3}\right)$. Using equation (7), the basic nature of the effect can indeed be foreseen. One can write:

$\alpha_{\mathrm{Ge}} / \alpha_{\mathrm{Sn}}=\mu_{\mathrm{Sn}}^{*} / \mu_{\mathrm{Ge}}^{*}$

On the other hand, $\mu^{*}$ depends upon the carrier mobility, the carrier effective mass, and the scattering cross section $Q$ according to:

$\mu^{*}=\mathrm{e}^{2} /\left(2 \mathrm{~m}_{\mathrm{N}} \mathrm{n}^{2} \mu \mathrm{Q}^{2}\right)$

TABLE II

Room temperature resistivities, carrier concentrations and carrier mobilities for undoped and Sn or Ge doped $\mathrm{In}_{2} \mathrm{O}_{3}$ ceramics [3]. The ratio $\mathrm{M} /(\mathrm{In}+\mathrm{Sn})$ has same meaning as in table $\mathrm{I}$.

\begin{tabular}{|c|c|c|c|c|}
\hline $\begin{array}{l}M /(\mathrm{In}+\mathrm{M}) \text { ratio } \\
(\mathrm{M}=\mathrm{Sn} \text { or } \mathrm{Ge})\end{array}$ & $\begin{array}{l}\text { Sample } \\
\text { symbol. }\end{array}$ & $\begin{array}{l}\mu \\
\left(\mathrm{cm}^{2} \mathrm{v}^{-1} \mathrm{~s}^{-1}\right)\end{array}$ & $\begin{array}{l}\mathrm{n} \\
\left(\mathrm{cm}^{-3}\right)\end{array}$ & $\begin{array}{l}\sigma \\
\left(\mathrm{cm}^{-1} \Omega^{-1}\right)\end{array}$ \\
\hline $\begin{array}{l}\mathrm{Sn} /(\mathrm{In}+\mathrm{Sn})=0 \\
\text { sintered at } 1100^{\circ} \mathrm{C}\end{array}$ & $\mathrm{a}$ & 40 & $1.3 \times 10^{17}$ & $8.32 \times 10^{-}$ \\
\hline $\begin{array}{l}\mathrm{Sn} /(\mathrm{In}+\mathrm{Sn})=0 \\
\text { sintered at } 1200^{\circ} \mathrm{C}\end{array}$ & b & 45 & $1.5 \times 10^{17}$ & 1.08 \\
\hline $\begin{array}{l}\mathrm{Sn} /(\mathrm{In}+\mathrm{Sn})=0 \\
\text { sintered at } 1300^{\circ} \mathrm{C}\end{array}$ & c & 28 & $2.5 \times 10^{18}$ & $1.12 \times 10^{1}$ \\
\hline $\begin{array}{l}\mathrm{Sn} /(\mathrm{In}+\mathrm{Sn})=0 \\
\text { sintered at } 1350^{\circ} \mathrm{C}\end{array}$ & d & 25 & $4.0 \times 10^{17}$ & 1.6 \\
\hline $\mathrm{Sn} /(\mathrm{In}+\mathrm{Sn})=0.125$ & e & 35.1 & $4.5 \times 10^{19}$ & $2.53 \times 10^{2}$ \\
\hline Sn $(I n+S n)=0.25$ & f & 30.9 & $1 \times 10^{20}$ & $4.94 \times 10^{2}$ \\
\hline $\operatorname{Sn}(\mathrm{In}+\mathrm{Sn})=0.5$ & g & 29 & $1.86 \times 10^{20}$ & $8.63 \times 10^{2}$ \\
\hline $\operatorname{Sn}(\operatorname{In}+\operatorname{Sn})=1$ & $\mathrm{~h}$ & 28 & $1.9 \times 10^{20}$ & $8.51 \times 10^{2}$ \\
\hline$S n(I n+S n)=2.5$ & $\mathrm{i}$ & 25 & $1.91 \times 10^{20}$ & $7.64 \times 10^{2}$ \\
\hline $\mathrm{Ge} /(\mathrm{In}+\mathrm{Ge})=0.125$ & $\mathrm{j}$ & 45 & $3.2 \times 10^{19}$ & $2.3 \times 10^{2}$ \\
\hline $\mathrm{Ge} /(\mathrm{In}+\mathrm{Ge})=0.25$ & $\mathrm{k}$ & 50 & $8.0 \times 10^{19}$ & $6.4 \times 10^{2}$ \\
\hline $\mathrm{Ge} /(\mathrm{In}+\mathrm{Ge})=0.5$ & 1 & 55 & $1.8 \times 10^{20}$ & $1.58 \times 10^{3}$ \\
\hline $\mathrm{Ge} /(\mathrm{In}+\mathrm{Ge})=1$ & $\mathrm{~m}$ & 52 & $1.88 \times 10^{20}$ & $1.56 \times 10^{3}$ \\
\hline $\mathrm{Ge} /(\mathrm{In}+\mathrm{Ge})=2.5$ & $\mathrm{n}$ & 50 & $1.9 \times 10^{20}$ & $1.52 \times 10^{3}$ \\
\hline
\end{tabular}




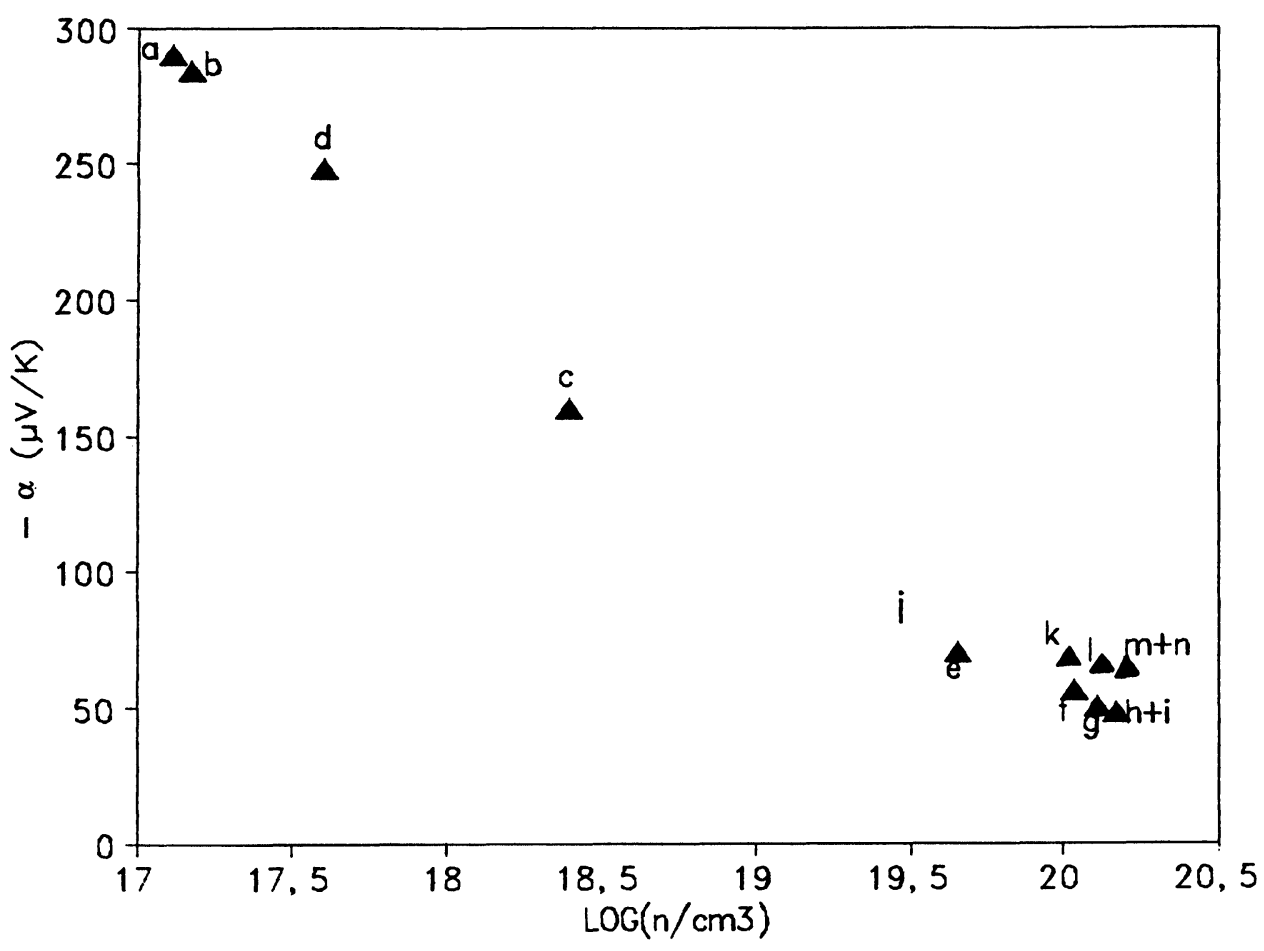

FIGURE 2 Dependence of the thermoelectric power on the electron density in undoped and Sn or Ge doped $\mathrm{In}_{2} \mathrm{O}_{3}$ ceramics at $300 \mathrm{~K}$. The sample symbolization is similar to that depicted in table II.

Consequently, we can obtain the following expression after certain transformations:

$\alpha_{\mathrm{Ge}} / \alpha_{\mathrm{Sn}}=\left(\mu_{\mathrm{Ge}} / \mu_{\mathrm{Sn}}\right)^{2}\left(\mathrm{Q}_{\mathrm{Ge}} / \mathrm{Q}_{\mathrm{Sn}}\right)^{2}$

The ratio of the scattering cross sections is not known exactly, but we can reasonably assume that it is less than unity; thereby the ratio between the thermoelectric power of germanium-doped and tin-doped samples will be lower than the square of the mobility-ratio.

\section{CONCLUSIONS}

We must now emphasize again that, most interestingly, the $\alpha$ values observed for $\mathrm{In}_{2} \mathrm{O}_{3}$ heavily doped with $\mathrm{Ge}$ are higher than those observed for $\operatorname{In}_{2} \mathrm{O}_{3}$ heavily doped with $\mathrm{Sn}$ : this result gives another strong evidence, as the Hall effect measurements (table II), of the enhanced carrier mobility in Ge-doped $\operatorname{In}_{2} \mathrm{O}_{3}$ (according to (11)). It clearly means that the optoelectronic properties of the widely used "conventional" ITO (ITO symbolizing, as pointed above, Sn doped $\mathrm{In}_{2} \mathrm{O}_{3}$ ) films should be improved if $\mathrm{Sn}$ is partially, or totally, substituted by Ge. 
Finally let us note that, for similar carrier concentrations, the values of the thermoelectric power of polycrystalline ceramic samples are higher than those of the related single crystals. This difference would be depicted by equation (10) and, thereby, would arise from the lower effective mass and scattering cross section occurring for single crystals.

\section{REFERENCES}

1. K.L. Chopra, S. Major and D.K. Pandya, Thin Solid Films, 102, 1-46 (1983), and references therein.

2. S.J. Wen, G. Couturier, J.P. Chaminade, E. Marquestaut, J. Claverie and P. Hagenmuller, J. Solid State Chem. (accepted 1992), and references therein.

3. S.J. Wen, G. Campet, J. Portier, G. Couturier, J.B. Goodenough, Mat. Sci. and Eng. B, 14, 921 (1992), and references therein.

4. S.J. Wen, G. Couturier, G. Campet, J. Portier and J. Claverie, Phys. Stat. Sol. (a) 130, 407 (1992), and references therein.

5. W. Ehrenberg, Electric Conduction in Semiconductors and Metals, Oxford University Press, 1958.

6. J.P. Remeika and E.G. Spencer, J. Appl. Phys., 35 (1964) 2803.

7. R.L. Weiher, J. Appl. Phys., 33, (1962) 2834.

8. P. Dordor, E. Marquestaut, Rev. Phys. Appl., 15 (1980) 1607.

9. S.J. Wen, Doctorat Thesis, Bordeaux University (1992). 

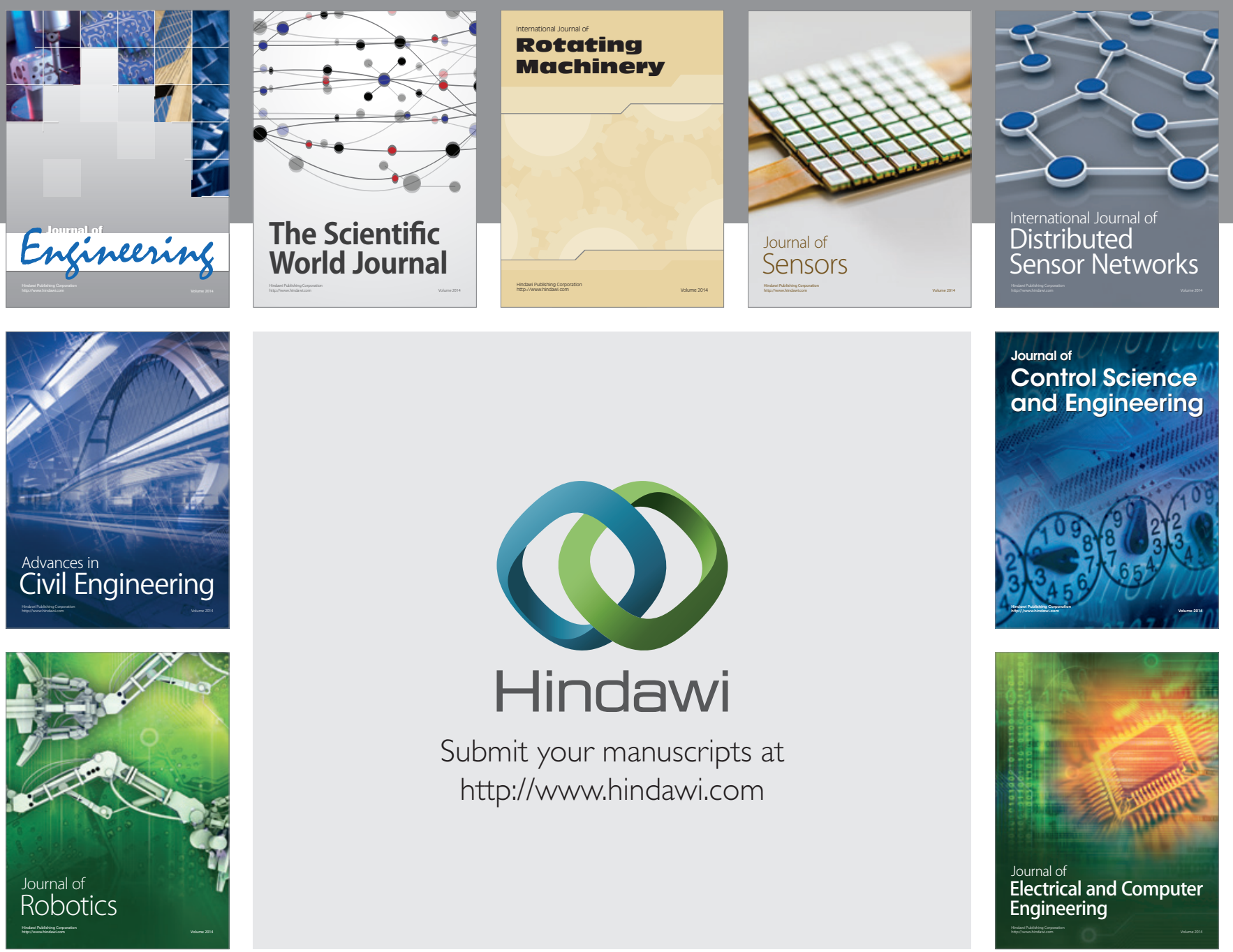

Submit your manuscripts at

http://www.hindawi.com
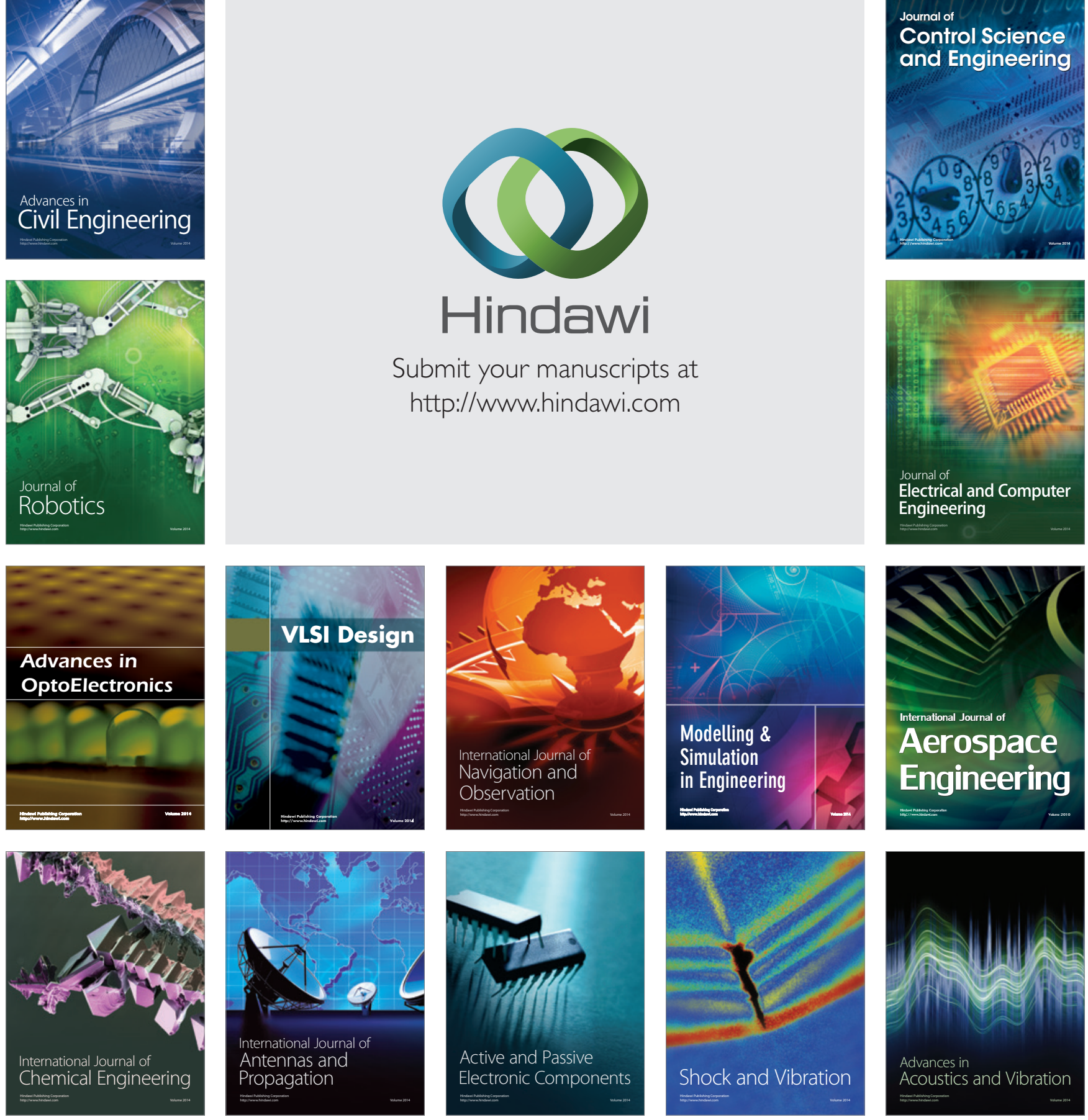